\title{
Building Down: Disassembling a Company Town
}

\author{
CAITLIN TANGEMAN \\ University of Nebraska-Lincoln
}

\author{
DAVID KARLE \\ University of Nebraska-Lincoln
}

On October 3, 2016, two decentralized consumer-based retail stores merged when Bass Pro Shops acquired Cabela's for $\$ \mathbf{5 . 5}$ billion. Following the merger, it is unlikely that Bass Pro Shops will elect to retain the Cabela's headquarters or retail store in Sidney, Nebraska, both to avoid maintaining duplicate headquarters and to target more profitable retail locations. As Sidney braces for its uncertain future, the city needs to address the artifacts of corporate, consumer-based urbanism that have resulted from Cabela's presence. Instead of attempting to maintain, service, or repair the artifacts, a more radical solution was considered. One method for combating the inevitable downward spiral resulting from the loss of the Cabela's headquarters, retail store, and distribution center in Sidney would be to adopt new forms, logics, and economies of subtraction. This would soften the transition of the community from its current state to a post-Cabela's condition while mitigating the typical effects of decline seen throughout shrinking communities. A proposed framework for subtraction would embrace decline, allowing the community to shrink or contract in a more gradual and productive way. The proposed subtraction scenarios include sites, strategies, tactics, user-narratives, and a framework. The concluding framework takes into account suspending and evolving economies and flexible systems of organization. The scenarios are meant to bring about awareness as much as to speculate on Sidney's future economic and built environment. Sidney provides an extreme case study of decentralized consumerism with which to apply potential alternatives to the typical pattern of decline.

\section{INTRODUCTION}

A vast majority of the built environment throughout the United States consists of cheaply constructed standalone buildings, many of which take the form of office parks, big box stores, storage facilities, and strip malls. Utilizing off-the-shelf construction techniques and prefabricated systems, these buildings have become one of the most flexible and quickly constructed forms of architecture in the built environment. The construction and occupation of these buildings, although grounded in formulaic market-driven data, is often shortlived due to changes in cultural, market, and global trends. What, if anything, should be done with these aging artifacts resulting from consumer patterns of urbanism? Should these cheaply constructed buildings be maintained, serviced, repaired, or reused? The architectural relicts of corporate America currently occupy the majority of our built environment, and according to Ellen Dunham-Jones, they will become the discipline's next major architectural project. ${ }^{1}$ Instead of attempting to maintain, service, or repair these overscaled buildings, might we consider a more responsive act of deconstruction or disassembly? Instead of continually tackling the progressive future of building the new, the architecture discipline must challenge traditional models of design.

\section{DECENTRALIZED CONSUMERISM}

One of the largest participants is the new hybrid model of decentralized consumerism occupying highway off-ramps across North America. These landscapes are decentrally located to maximize their consumer attraction as destinations, often culminating in a monotown organized around the franchise space of the big box retail store. These communities thrive on aspects of both tourism and consumerism. Stores like Cabela's and its competitor, Bass Pro Shops-both outdoor sporting goods retail chains-represent a unique model that simultaneously acts as a retail store, museum, and tourist destination. (Bass Pro Shops ranks as Missouri's top tourist destination.) Part shopping experience and part tourist attraction, this Disneyland-effect provides the consumer or "guest" the opportunity to experience in-store aquariums, dioramas, and horse corrals, and to even practice archery. The highway locations of these retail stores and distribution centers have grown into new economic bases for small towns, sprouting new restaurants, hotels, housing, and entertainment for the millions of consumers per year who visit each store.

Even though the architecture discipline has seldom participated in the planning or design of these cheaply constructed buildings, the discipline should acknowledge the ethical imperative and opportunity to transform the future of the built environment of decentralized America. As Rem Koolhaas has stated, the vast countryside outside of urban centers is an "undescribed field [that] nobody thinks about,"2 a place that is physically and conceptually left behind by the discipline, ${ }^{3}$ and a space which should be reconsidered for the future. One such monotown of cheaply constructed buildings facing an uncertain future is the rural town of Sidney, Nebraska, home to the former Cabela's headquarters. Sidney will be presented as a case study for new models and forms of subtractive economies seeking to embrace decline, speculating on strategies for a rural community to shrink in a more gradual and productive way. 


\section{A COMPANY TOWN}

Cabela's is the largest mail-order, retail, and internet outdoor outfitter in the world, and since the founding of its first physical retail store in 1991, the company has grown to eighty-five stores in thirty-six states and six provinces across America and Canada. Small towns along the highway are transformed into decentralized destination nodes for consumer experiences based on the "Cabela's Site Criteria," which considers the number of company catalog orders and fishing/hunting licenses in a region, in addition to the amount of interstate frontage and highway visibility for a given site. Potential sites are also required to be within 20 miles of a metro area, to have 1 million people within a 30-mile radius, and to be at least a 60-minute drive from another Cabela's retail store. In this decentralized model, Cabela's seeks to maximize both logistical product distribution and consumer purchasing habits. But with the decentralized model comes some risk.

The logistically controlled franchise space associated with decentralized consumerism exhibits negative effects on the lack of industrial diversity on small monotowns along the highway. The Cabela's headquarters in the rural community of Sidney, Nebraska was not necessarily determined based on logistics, but out of convenience for the company's founder, who had ties to the Sidney community. Cabela's exerts a strong influence on the town of Sidney, with the community coming very close to the definition of a "company town." Development has ballooned in Sidney over the past few decades as housing, hotels, restaurants, fast food chains, truck stops, and supercenters have sprung up near the headquarters. The City of Sidney Financial Statements for 2013-2014 indicate that the town of Sidney had more jobs $(8,000)$ than residents $(6,757),{ }^{4}$ with nearly half of these workers commuting from distances up to 60 miles. ${ }^{5}$ Until October 2016, Sidney grew faster than any other community in western Nebraska, with its population increasing 7.6\% between 2000 and $2010 .{ }^{6}$ Additionally, the city ranks first in Nebraska and among the top ten in the United States for the highest number of jobs per capita. ${ }^{7}$

This growth and high employment is entirely due to the presence of the Cabela's headquarters, distribution, and retail center. Cabela's corporate offices in Sidney alone employ over 1,500 people, while distribution accounts for around 200 employees and the retail store employs another 125 people, according to Nathan Borowski, a communications specialist at Cabela's headquarters. ${ }^{8}$ In addition to providing jobs for nearly a quarter of Sidney's population (as well as for many surrounding communities) the Sidney Cabela's is estimated to attract over 1 million visitors per year. ${ }^{9}$

\section{THE \$5.5 BILLION MERGER}

On October 3, 2016 two decentralized consumer-based retail stores merged when Bass Pro Shops acquired Cabela's for $\$ 5.5$ billion. The merger means that many of Cabela's current operations will become redundant, and as Creighton
University Professor of Economics Ernie Goss predicts, "It's very unlikely that those central office facilities functions will be combined." ${ }^{10}$ The merging of these two franchises will continue to occupy and transform the United States hinterland by the hyper-rational movement of capital and consumers by corporate interests.

It is unlikely that Bass Pro Shops will elect to retain the Sidney retail store, since financial analyses have demonstrated the negative effects of retail saturation on the Cabela's stores. Since the stores are marketed as tourist destinations, oversaturating the market reduces the destination effect. Sidney's store does not fit either Bass Pro Shops' or Cabela's typical site selection model, which locates stores in small communities located in close proximity to major metropolitan areas. It is therefore unlikely that the Sidney retail store ranks highly in profits when compared to the company's other stores, since it is not strategically located in an area likely to reap the most rewards.

Bass Pro Shops pulling Cabela's out of Sidney would not only result in the loss of the enormous number of jobs the company provides, but a loss of the large number of tourists drawn to the area due to destination retail, yielding disastrous effects on the town's service sector. With the potential loss of Cabela's and the large number of visitors it attracts, the area's balloon of development will pop and the housing market risks collapse. Cabela's has inflated market rates in Sidney, with rental prices comparable to regional cities like Omaha, the population of which is nearly 64 times greater than Sidney's. ${ }^{11}$ As of summer 2017, signs of decline are already beginning to show in the community. Kevin Ross, a realtor from a neighboring town, indicated that "Many people have already abandoned ship and listed their homes, [putting] downward pressure on all real estate prices." ${ }^{\prime 12}$ For Sale signs and U-Haul trucks are frequent sights around the town, and large development projects have been put on hold, including a 700-home housing development, a new 82-unit Holiday Inn Express that was to provide a conference center primarily for corporate use by Cabela's (see Figure 1).

As Sidney braces for its uncertain future, the city must tackle the question faced by so many other communities flooded by cheaply constructed decentralized consumer buildings: how should they address the artifacts of corporate, consumerbased urbanism? The challenge for a monotown like Sidney lies in adapting to economic fluctuation and corporate instability, but instead of attempting to maintain, service, or repair the artifacts, a more responsive solution might prove more effective.

Sidney provides an opportune case study for considering a new economy of subtraction, as discussed by architect and urbanist Keller Easterling in her 2014 book, Subtraction: Critical Spatial Practice 4. Easterling suggests that "subtraction 

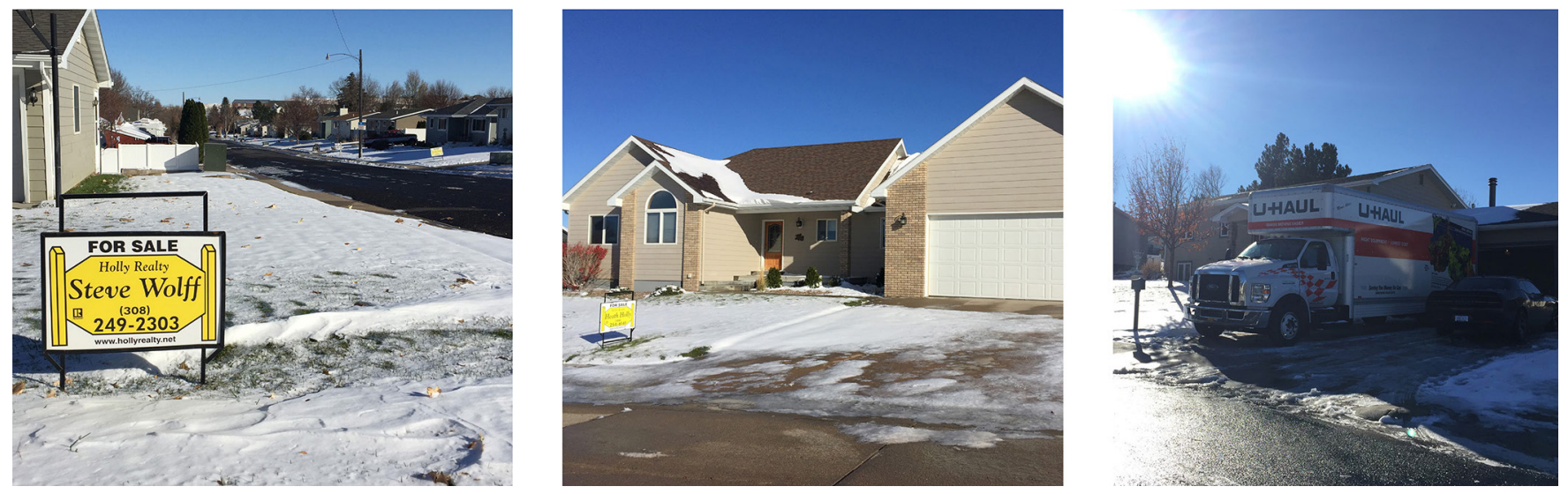

Figure 1: Signs of Decline. Halted construction at The Ranch housing development (top), and For Sale signs and U-Haul trucks throughout Sidney (bottom). Photos by the author, winter 2017.

is not simply absence, but a moment in a set of exchanges and advances, aggression and attritions that are part of the most active organization." ${ }^{13}$ Easterling further expands the role of architects and preservationists to include managing the subtraction or contraction of development at the scale of architecture and urbanism. While the design professions are typically described by the objects they produce, a challenge to the idea of building up or building new lies in the critical practice of building down, an essential concept for the age of increasing architectural relicts and unstable economies. Subtraction, instead of being seen as failure or loss, should be viewed as a sign of growth, and rather than being viewed as a form of erasure, it should be considered a new form of exchange. ${ }^{14}$

\section{ECONOMIES OF SUBTRACTION: POST-CABELA'S}

One method of combating the inevitable downward spiral resulting from the loss of the Cabela's headquarters, retail store, and distribution center in Sidney would be to adopt new forms, logics, and economies of subtraction. This would soften the transition of the community into a post-Cabela's state while mitigating the typical effects of decline seen throughout shrinking communities. A proposed framework for subtraction would embrace decline, allowing rural communities to shrink in a more gradual and productive way.

\section{SUBTRACTION}

The idea of subtraction in architecture has gained in popularity within the discipline as a method for addressing depopulation and decline. The necessity of subtraction can be seen in the Storefront of Art and Architecture's 2016 competition Call for Ideas: Taking Buildings Down, which states that to better understand the life cycles of our built environment we must explore and embrace the critical practice of subtraction. ${ }^{15}$ As local and global communities continue to face decisions of reuse and repair in their aging communities, methods of subtraction within the design field become a vital discussion. Subtraction through deconstruction has been tested by several shrinking cities within the last decade, specifically those in the Rust Belt. Additionally, recent Great Plains population calculations report depopulation at a scale that is unprecedented in U.S. history, ${ }^{16}$ making them prime candidates for a sustained focus on subtraction to avoid the loss of small communities throughout the region due to attrition.

Subtraction constitutes a flexible system that allows for a more fluid transition of population, employment, and economy. Currently there exist local and regional economies of subtraction sustained by companies whose focus areas include demolition, deconstruction, disassembly, reuse, and salvaged materials. To support these efforts, grant funding for deconstruction projects is available at both the federal and state levels, ${ }^{17}$ especially since the deconstruction component of subtraction is almost always more expensive to pursue than demolition, primarily due to increased labor costs and the longer timeframe associated with deconstruction. However, according to Ted Reiff, president of The ReUse People, a nationwide nonprofit deconstruction company based in Oakland, California, tax savings can be accrued through the sale of materials to offset the cost of deconstruction. ${ }^{18}$ For example, a single-family home would cost about $\$ 11,000$ to demolish and $\$ 13,000$ to deconstruct, but a tax benefit of $28 \%$ on $\$ 50,000$ of materials harvested from the deconstructed home will provide $\$ 14,000$ in tax savings. That savings will offset the expenses from the deconstruction process and actually provide a positive return. Similar offset savings can be seen with the hotel and retail store. By offsetting costs and creating new economies and employment, subtraction becomes a viable option for helping small communities shrink in a gradual and productive manner.

Keller Easterling, who has studied the logistics of the subtraction economy for nearly two decades, explains that "[by] initiating a number of temporal exchanges that can be constructively used, converted, or traded, subtraction opens onto an expanded field of form making. With this expanded artistic repertoire, architecture can design buildings, cities, and landscapes not just as collections of objects, but also as activities-not only object forms but also active forms." ${ }^{19}$ By applying Easterling's methods of subtraction, designers can better address issues of growth and logistical organizations 
through a system of active forms, which she defines as "time released protocols that generate or manage a stream of objects and space," ${ }^{\prime 20}$ as opposed to static and inflexible object forms, which are more common within the architectural discipline.

Active forms respond to the ebbs and flows of shifting economies and patterns of urbanism, making them ideal for built environments such as Sidney's whose futures hang in the balance. Shifting a designer's mindset from object forms to active forms inverts the usual protocols for addressing a shrinking city's future, and considering design as a system or framework based on time-released protocols requires a recalibration towards responsive programming, building down (deconstruction), and flexibility that object forms cannot offer.

By applying the active form of subtraction as discussed by Easterling to a shrinking city, an alternative economy can be created by engaging deconstruction and salvage industries, stabilizing the community while simultaneously deconstructing it. This alternative practice of designing for subtraction provides a mechanism for addressing the resultant artifacts of consumer-based patterns of urbanism. The subtraction economy should be considered firstly as a design challenge, then as a major industry, a lucrative emergent global enterprise, a source of employment, and a political instrument. ${ }^{21}$

Deconstruction can be applied to the larger system of subtraction to effectively shrink a community through more gradual, deliberate means, as the Sidney case study will show.

The forthcoming subtraction scenarios for the urbanism produced by Cabela's presence in Sidney include strategies and tactics for suspending the value of buildings, materials, programs, and labor forces.

\section{SUBTRACTION SCENARIOS}

The proposed subtraction scenarios engage three sites, including strategies, tactics, user-narratives, and a scenario framework to produce active forms continually evolving to the conditions within Sidney. The following scenarios are not meant to provide answers, but rather create awareness, speculate, and ask questions about what could happen to Sidney's future economic and built environment as it relates to decentralized consumerism. By providing insight from an architectural point of view, the speculations are meant to advance architectural thinking and discourse as a way of confronting a critical issue facing the discipline. For the architecture discipline to remain relevant we must challenge and foster new architectural thinking, not just continue applying new construction. The speculation of subtraction provides a new lens for confronting recent crises, catastrophes, and population shifts.

\section{SCENARIO SITES, STRATEGIES, AND TACTICS}

Potential sites for unbuilding in Sidney include first, the single-family home, abandoned by former Cabela's employees. Second is the hotel, the unused commercial development built to support Cabela's consumers, and third is the Cabela's retail store, a building no longer needed after the company's exit. Each site includes four configurations with three strategies and two tactics. The strategies include disassembly, material harvesting, and adaptive re-use. The tactics include complete or partial disassembly, harvested material for distribution or reconstruction, and complete or partial re-use. These strategies and tactics have the four desired outcomes of temporary employment through disassembly, re-centralizing the community through disassembly and re-construction, generating revenue from salvaged material, and integrating temporary programs based on current and projected needs that support the above strategies (see Figure 2).

\section{SCENARIO NARRATIVES}

To identify how each related user group might be affected by the proposed scenarios, three user-narratives were generated, projecting the intended path and outcome through the lens of a specific primary user group. All three narratives begin with the loss of Cabela's and the subsequent loss of jobs within the community. The first user-narrative includes the visiting outdoor recreationist (hunter, bird watcher, etc.) who previously travelled to Sidney specifically for Cabela's. The second user-narrative follows the former Cabela's employee who has lost his or her job after the company's exit, and following him or her through unemployment and home foreclosure. The third user-narrative involves the interstate travelers and truckers passing by Sidney on I-80, long-term users who will likely remain even after Sidney's proposed deconstruction. This user-narrative will use the former Cabela's retail store after it has been abandoned. All three user-narratives play out within the scenario framework across space, time, and scale of subtraction (see Figure 3).

\section{SCENARIO FRAMEWORK}

Starting with the present and forecasting more than twentyfive years into the future, the scenario framework or matrix positions five disassembly phases against the three user narratives and sites (single family home, hotel, and Cabela's retail store) to project future use as they are disassembled over time (see Figure 4).

Throughout the five disassembly phases, new programs are implemented that take advantage of the partially deconstructed community to allow for more strategic decline. Phase zero is the existing condition. Based on the user narratives, phases one through three utilize strategies and tactics from the subtraction scenarios to centralize the community, suspend the value of the site, introduce new programs, and support related user-groups. The single-family home is strategically deconstructed, leaving only the foundation walls for 


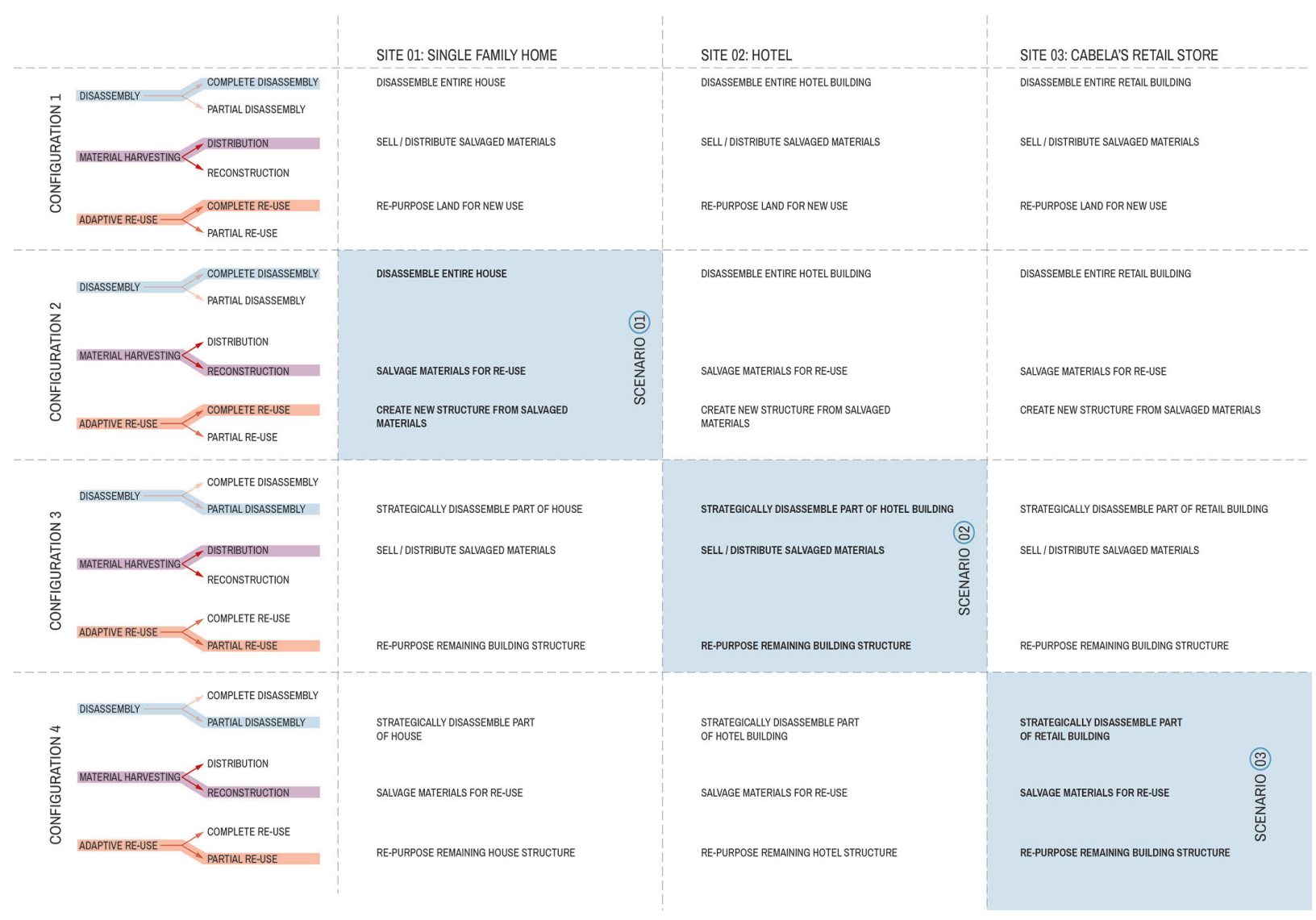

Figure 2: Subtraction scenarios, strategies, and tactics are organized to address artifacts resulting from consumer patterns of urbanism (home, hotel, and retail store). Photos (winter 2017) and illustration by the author.

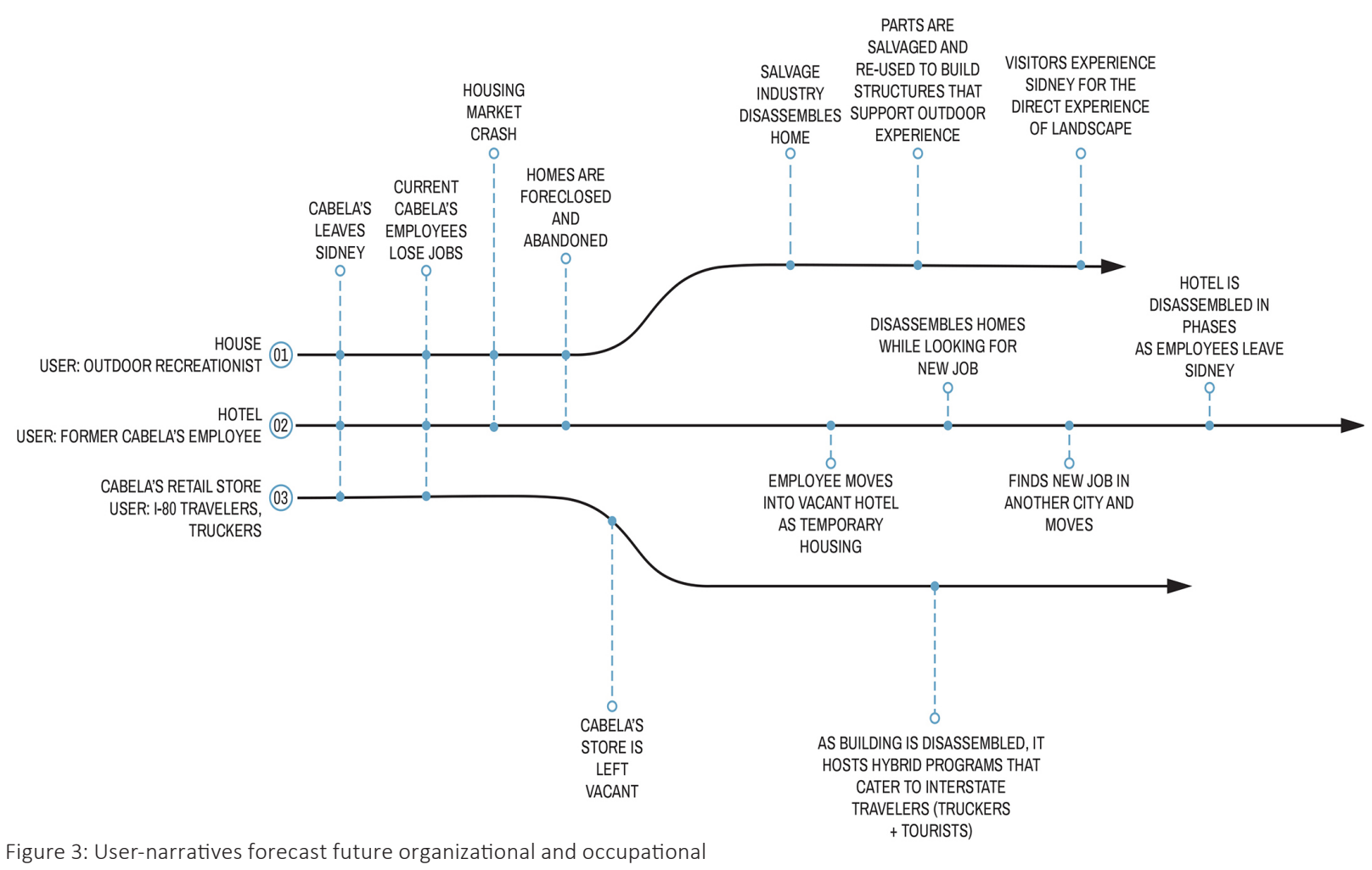

scenarios for a non-diversified economy. Illustration by the author. 


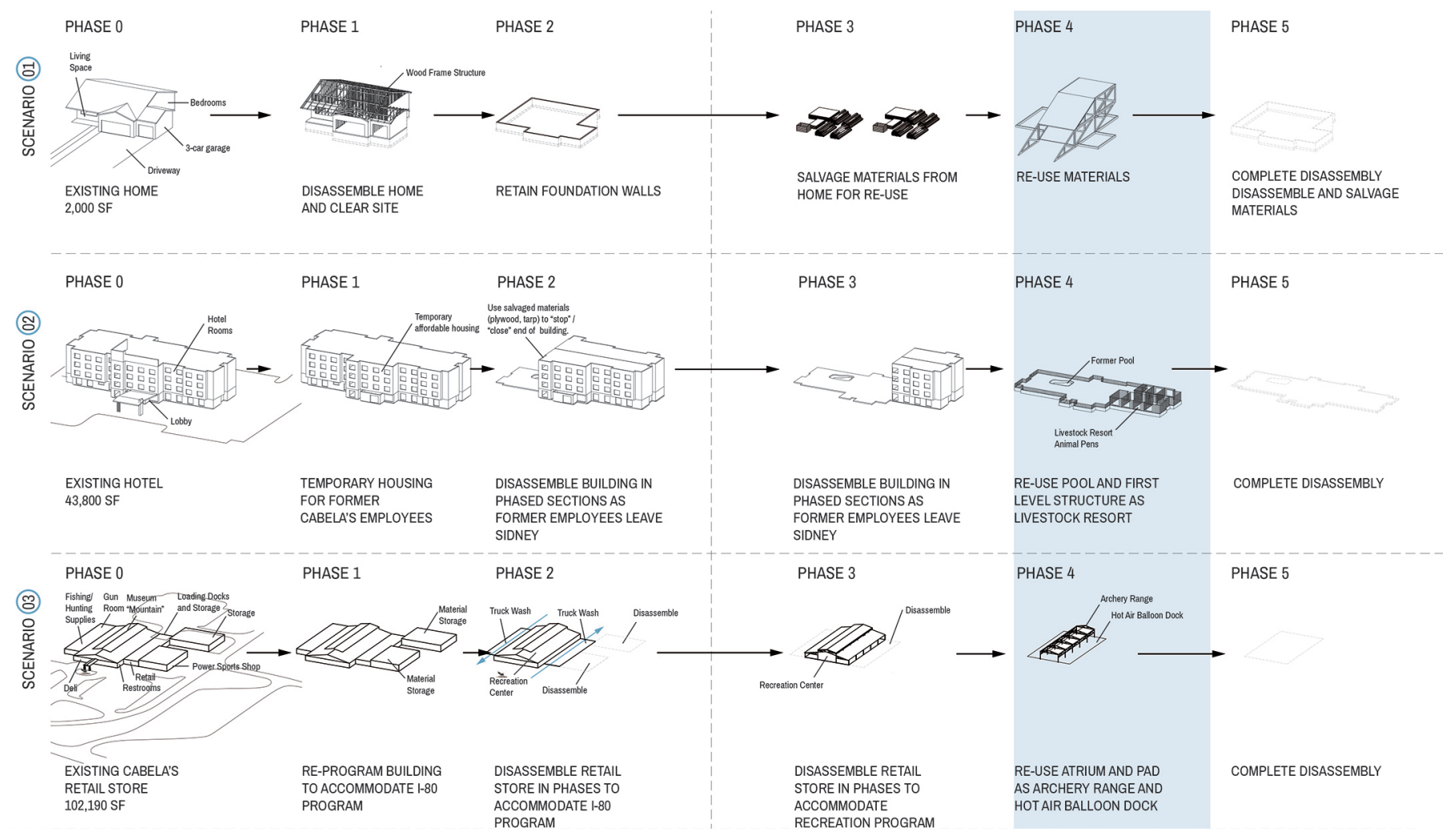

Figure 4: Scenario framework. Illustration by the author.

future reuse. The hotel initially acts as temporary housing for former employees and is then strategically disassembled over time. Finally, the Cabela's retail store is reprogrammed first as material storage to support the deconstruction industry, then as a hybrid Truck Wash and Outdoor Recreation Center to support Interstate- 80 users. Phase four, situated twenty-five-plus years in the future, is the focus for further investigation and speculative proposals (see Figure 5) as it proposes re-use strategies for harvested building materials and re-appropriation of existing programs.

During Phase four the project aims to target the third usernarrative, the Interstate 80 occupant, and allows users to slow down and experience the landscape of what much of the country views as flyover territory. While this once seemingly leftover territory has been forgotten, the proposed strategies will bring a new awareness and appreciation of this working landscape. The visitor or guest will engage the natural landscape, indigenous wildlife, agriculture and ranching practices, and the historic ruins of Sidney as the partially deconstructed town is transformed into an entertainment opportunity with an archery range, livestock resort, hot air balloon rides, and more.

The new programs on site respond to the culture and history of the Great Plains and more specifically to the former pattern of urbanism created by Cabela's. The strategies are intended to suspend the subtraction process and take advantage of the re-use of material and fragmented spaces through a system of active forms. The site's former programs are maintained as either direct, altered, or inverted representations of their original intent, continuing to bring awareness to the environment and the earlier monotown. For example, the Cabela's archery range is maintained, as is the water tower (re-purposed as an observation tower), and the destination effect of the retail store is maintained through the experience of the natural landscape rather than the experience of shopping. Additionally, Cabela's taxidermy museum is maintained through the use of giant animal-shaped balloons that reinforce the destination experience while maintaining the iconic presence that Cabela's once had on the site.

Past programs are also maintained in the new design through inversion. For example, the hunting ideology of Cabela's is reversed so that instead of providing hunting goods the site becomes a wildlife sanctuary that protects animals from hunting. Additionally, deconstructed materials from former homes are made into viewing stands that act as a means for passive observation rather than active hunting. The viewing stands, constructed on top of a former home's foundation, reflect an altered awareness of the program that once inhabited the site. Where bedrooms once provided a place for humans to sleep, a docking station for agricultural drones is provided, and autonomous machines now inhabit the space where a garage previously housed vehicles. 

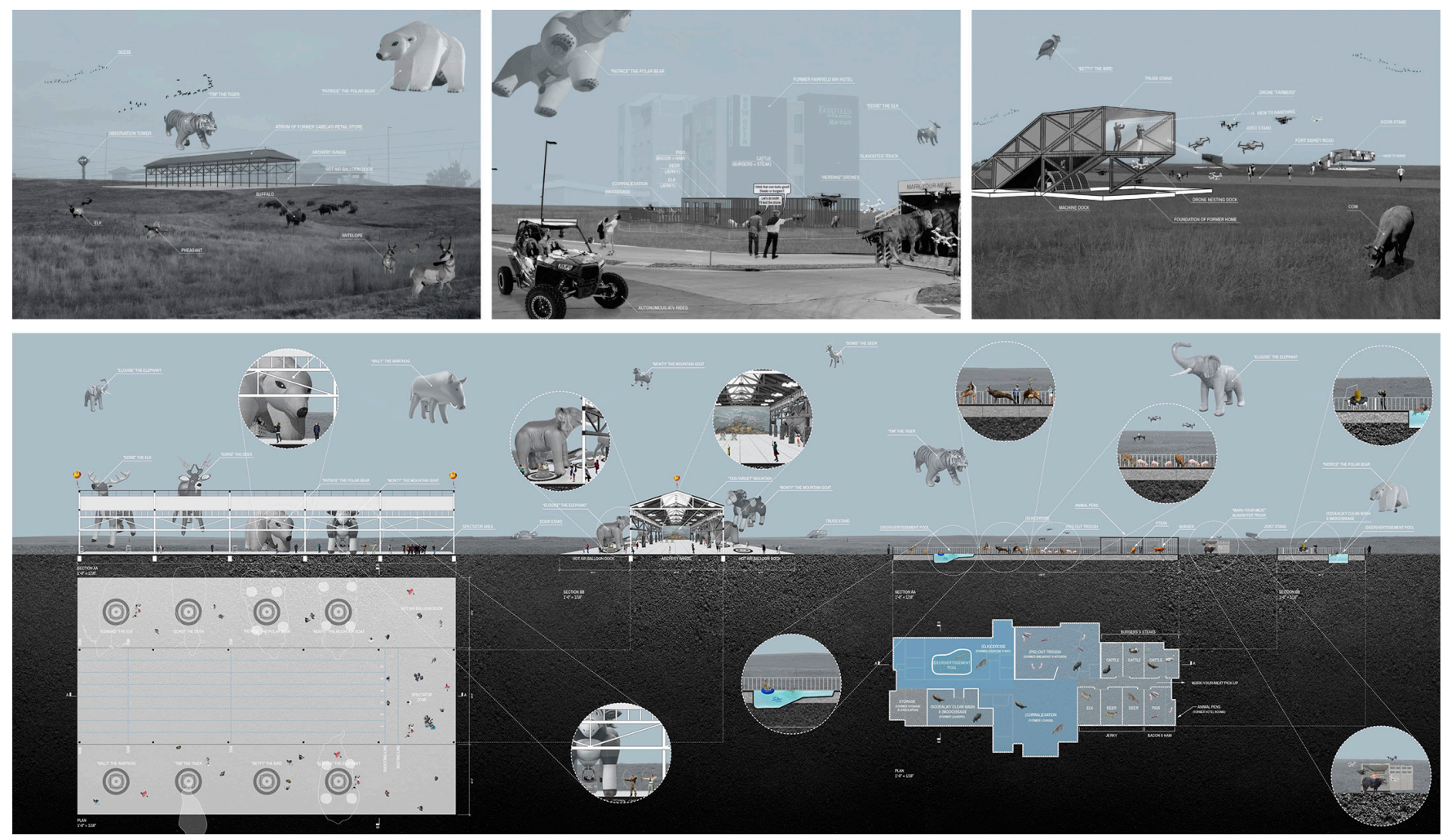

Figure 5: Phase four future projections. Top, Left to right: Repurposed retail store as archery range/hot air balloon dock, repurposed hotel as livestock resort, and repurposed homes as viewing stands. Bottom Repurposed retail store and hotel shown in section, providing new inhabitants and inverted programs. The repurposed single-family homes with viewing stands built on top can be seen in the background. Illustrations by the author.

Finally, visitors can observe the Livestock Resort that draws from the program in the former hotel, inverting a program once used for humans into a program used for animals. The Livestock Resort houses animals in the former first-floor hotel rooms, has an animal feeding area located at the site of the former breakfast nook, and uses the former pool as an animal recreational pool.

Ultimately, in Phase five, the sites are allowed to revert back to a natural, agrarian state with no human population, alluding to the "Buffalo Commons" movement proposed by Drs. Frank and Deborah Popper in the late 1980s that sought to re-establish the American frontier through prairie reserves and ecological corridors. ${ }^{22}$ As corporate models of logical operations continue to impact remote communities, we must account for not only the short-term benefits of logistical operations, but the irreversible long-term impacts.

\section{CONCLUSION}

States of disrepair or decline are widespread, not only throughout the rural Midwest, but throughout the world. A significant number of these cases have been attributed to the collapse of non-diversified economies, caused in part by changes in corporate structure, retail markets, or consumer habits and culture. This is a reality of our built environment, and the research presented here aims to contribute to the subtraction discourse through the specific case study of Sidney via a close description and analysis of the city and its building types. General principles that can be drawn from this case study include:

- Strategies for disassembly, material harvesting, and adaptive re-use

- Stactics for complete or partial disassembly, harvested material for distribution or reconstruction, and complete or partial re-use

- Outcomes of temporary employment through disassembly, recentralizing the community through disassembly and reconstruction, generating revenue from salvaged material, and integrating temporary programs

- Identification of federal and state grants

- Shifting designer's mindset from object forms to active forms.

Sidney, Nebraska provides an extreme case study of decentralized consumerism with which to apply potential alternatives to the typical pattern of decline. Using strategies of time-released protocols and active forms, subtraction scenarios constitute several acts of repair on a small rural town. Embracing decline as an opportunity, the research and framework can be adapted and applied to similar situations of disrepair facing communities across the United States and the 
world. The proposed recommendations, although speculative in nature, are meant to provide informed alternatives for the architecture discipline to address issues within the built environment via unbuilding.

\section{ENDNOTES}

1 Ellen Dunham-Jones, "Seventy-five Percent," Harvard Design Magazine, No. 12 (Fall 2000): 1.

2 Rem Koolhaas, Architect Rem Koolhaas, October 19, 2011. Charlie Rose.

3 For more information see, Rem Koolhaas's forthcoming Countryside exhibition at the Guggenheim, New York in 2019.

4 City of Sidney, Nebraska Financial Statements for the year ended September 30,2014 and Accountant's Opinion Thereon, PDF, http://www.cityofsidney. org/ArchiveCenter/ViewFile/Item/510, Accessed February 9, 2017.5. Susan Satterfield, "Livy and the Pax Deum," Classical Philology 111, no. 2 (April 2016): 170.

5 Sara Germano, "Cabela's Deal Spurs Uncertainty for Small Nebraska Town" "The Wall Street Journal, October 5, 2016, Accessed November 20, 2016, http://www.wsj.com/articles/ cabelasdeal-spurs-uncertainty-for-small-nebraska-town-1475659800.

6 Barbara Soderlin, "Even during Rapid Expansion, Cabela's Embraces Panhandle City as Home," Omaha World Herald, June 8, 2015, Accessed November 15, 2016, http://www.omaha.com/ money/even-during-rapid-expansion-cabela-sembraces-panhandle-city-as/article_98ab3fff-ebd7-566e-af45-3adc64470735. html.

7 The City of Sidney, Nebraska, Welcome to Sidney-Nebraska.com, Accessed November 21, 2016, http://www.sidney-nebraska.com/.

8 Nathan Borowski, “Cabela's Info," E-mail message to author, November 28 2016

9 Hunden Strategic Partners, Sidney, Nebraska Conference Center Feasibility Analysis, PDF,. October 2012, Accessed November 20, 2016, http://www. cityofsidney.org/documentcenter/view/474

10 Paige Yowell, Barbara Soderlin, and Janice Podsada, "Nice Homes That No One Wants to Buy? After Cabela's Sale, Sidney Braces for What Could Be 'terrible Effect' on Housing Market," Omaha World Herald, October 9, 2016, Accessed November 15, 2016, http://www.omaha.com/money/nice-homes-that-no-onewants-to-buy-after-cabela/article_1568441f-bd9f-5593-b056-013894fd13aa. html.

11 Barbara Soderlin, "Even during Rapid Expansion, Cabela's Embraces Panhandle City as Home," Omaha World Herald, June 8, 2015, Accessed November 15, 2016, http://www.omaha.com/ money/even-during-rapid-expansion-cabela-sembraces-panhandle-city-as/article_98ab3fff-ebd7-566e-af45-3adc64470735. html.

12 Paige Yowell, Barbara Soderlin, and Janice Podsada, "Nice Homes That No One Wants to Buy? After Cabela's Sale, Sidney Braces for What Could Be 'terrible Effect' on Housing Market," Omaha World Herald, October 9, 2016, Accessed November 15, 2016, http://www.omaha.com/ money/nice-homes-that-no-onewants-to-buy-after-cabela/article 1568441f-bd9f-5593-b056-013894fd13aa. html.

13 Keller Easterling, Subtraction: Critical Spatial Practice 4 (Berlin: Sternberg Press, 2014): 3,4 .

14 Ibid, 2.

15 Storefront of Art and Architecture, Call for Ideas: Taking Buildings Down Accessed on December 1, 2017, http://storefrontnews.org/programming/ call-for-ideas-taking-buildings-down/.

16 Dr. Larry Swanson, "Can the Path be Altered?: Salvaging and renewing Communities of Rural Plains" Rural Initiative Publications and Report. Paper 1 (2007).

17 At the federal level, grants are available from organizations such as the United States Department of Housing and Urban Development (HUD) and the United States Environmental Protection Agency (EPA) that can help to fund deconstruction projects. Funding is also available at the state level: in Nebraska, the Nebraska Department of Environmental Quality (NDEQ) provides funding through a grant application process that aids in the "deconstruction of abandoned buildings for cities of the second class, villages, and counties with a population of 5,000 or less." This grant, originally passed by the Nebraska Legislature in 2009, was created to "further encourage the recycling of building materials and decrease the amount of demolition material that is being disposed of in landfills," according to David Haldeman, NDEQ Waste Management Division Administrator.
18 Ted Reiff, "Deconstruction and Reuse Interview, The ReUse People," Telephone interview by the author, March 13, 2017.

19 Keller Easterling, Subtraction (Berlin: Sternberg Press, 2014), 37.

20 Ibid, 39-42

21 Ibid, 3.

22 "Buffalo Commons," Great Plains Restoration Council, accessed September 1 2017, http://gprc.org/research/buffalo-commons/\#.WbA3Jsh96UI. 